\title{
DIGITALIZATION AS A TOOL FOR MODERNIZING THE EDUCATIONAL PROCESS IN THE UNIVERSITY (SOCIAL AND PHILOSOPHICAL ANALYSIS)
}

\author{
Larisa Perevozchikova ${ }^{1}$, Alexey Radugin ${ }^{2}$, Evgenia Avdeenko ${ }^{3}$, Vasiliy Kukoba ${ }^{4}$ \\ ${ }^{1}$ Doctor of Philosophy, Professor, Voronezh State Technical University, 20 years of October Street, \\ 84, Voronezh, Russia, E-mail: perevozch@vgasu.vrn.ru \\ ${ }^{2}$ Doctor of Philosophy, Professor, Voronezh State Technical University, 20 years of October Street, \\ 84, Voronezh, Russia, E-mail: aradugin@yandex.ru \\ ${ }^{3}$ Candidate of Philosophy, Voronezh State Technical University, 20 years of October Street, 84, \\ Voronezh, Russia, E-mail: jjaane@yandex.ru \\ ${ }^{4}$ Graduate student majoring in history Voronezh State University, Russia, E-mail:vaas.777@mail.ru
}

\begin{abstract}
The article shows that the social transformation that modern society is going through makes it necessary to modernize it. Modernization of higher education plays a major role in the modernization of society. Digitalization should become a tool for modernizing higher education in the era of the Fourth Industrial Revolution. The authors set themselves the task on the basis of social and philosophical analysis to identify the essence and main directions and contradictions and risks of digitalization of the educational process in the modern university.

The theoretical analysis revealed the essence of the term "digitalization" and established a list of digital technologies significant for the development of society and defined and systematized a list of key digital competences of a modern specialist and identified contradictions and risks of the process of digitalization of the educational process in the university.
\end{abstract}

Keywords: modernization, digitalization, educational process in the university.

\section{INTRODUCTION}

The following circumstances determine the nature of the topic of the study. Firstly, the scale and pace of the world 's social transformation which creates increasing needs for knowledge and higher education and which are becoming essential factors for the economic and socio-cultural development of the individual and communities and nations. In this regard, higher education faces enormous tasks and requiring its radical qualitative transformation and renewal and giving it a relief expressed innovative orientation. No country can achieve real sustainable development on an endogenous basis without modern-day higher education and research institutions that create a critical mass of skilled and educated people, among other things, 
Proceedings of SOCIOINT 2020- 7th International Conference on Education and Education of Social Sciences, 15-17 June 2020

developing and poor countries cannot narrow the gap between them and industrialized countries.

The main advantage of a highly developed country is its human potential, which is largely determined by education. This is all the more relevant in today 's world, when the international weight and influence of States are increasingly determined not so much by the size of their territories or military power as by scientific and technical potential, the level of education and culture of the population, and the contribution to world civilization. There are factors that are now becoming decisive in order to ensure sustainable social and economic growth of the country in the long term. However, in order to ensure quality education at the present stage and in the perspective of its equal accessibility for all citizens, it is necessary to modernize the education system on the basis of effective interaction of education with the labour market. Tomorrow 's economy is an innovative economy of knowledge and knowledge-intensive technologies. Appropriate mechanisms should be established to prepare a sufficient pool of highly qualified specialists to bridge the widening gap between the content of education and educational technologies and the structure of the educational sector and the level of its personnel potential and the needs for innovative development of the country 's economy. Special role in strategic renewal of modern university. We should talk not only about reequipping IT-resources, but also about a kind of reset of human potential and upgrade of professional capital and improvement of corporate culture and socialization and communication of the educational institution and optimization of all its internal processes. Modern digital technologies provide new tools for the development of universities and other educational institutions around the world. Digitalization provides opportunities to share experience and knowledge, enabling people to learn more and make more informed decisions in their daily lives. Today, through digitalization, everyone can access information that was previously available only to experts and scientists. Every university in the information society must undergo a digital transformation regardless of the strategy chosen. Such a transformation lies not only in the introduction of IT solutions, but in general is a significant cultural and organizational change at the university. The transition to a digital university involves introducing more flexible and seamless processes and changing corporate culture and optimizing processes. The urgency in the need for digital transformation is explained by several factors. Firstly, at present almost all students belong to the generation of digital natives, they show a much greater tendency to apply new technologies in their daily life. It is especially concerned with IT and Internet technologies, as well as their application not only in the professional sphere, but also for socialization and communication. To sum up, digitalization of the university will make it more adapted for the target audience. This will definitely increase the competitiveness of the university in the education market and create additional value and attract students. Secondly, in a globalizing world we increase competition among universities, especially for top universities. In view of the globalization of the market, the struggle for a student will no longer take place within one country or cluster of countries, but at the international level. To sum up, the creation and preservation of the competitive advantage of the university will be determined by the timeliness of the introduction of new technologies and, as a result, readiness for fundamental shifts towards the educational system of the new generation. The need for digitalization is also dictated by the internal processes of the university to increase the efficiency of interaction of all its divisions. This is important for carrying out all the innovative and cultural changes required of the university in the transition to a modern educational model.

The demand for the ability to analyze systems and the dissemination of ideas and methods of process management and the increase in the number of jobs where it is necessary to set tasks and formalize methods of solving them - all this forces to redefine traditional educational results in the course of digital transformation of education. Achieving this goal is particularly relevant in view of the proliferation of cloud computing and the public high-speed Internet and the widespread introduction of smart digital tools and the use of artificial intelligence techniques and the widespread introduction of virtual reality technologies.

\section{METHODOLOGY}

In our view, the social and philosophical analysis of the educational process should be based on the interaction between the methodologies of civilization and modernization approaches. These approaches make it possible to record the object in a holistic manner with regard to a specific cultural and historical space and time and to consider it in substantive and contradictory manifestations. In the use of such a synthetic methodology, it is essential to understand the institution of education as a holistic system and to identify the determinants and mechanisms of its transformation. Within the framework of interaction, civilization and modernization methodologies and socio-philosophical study of this problem involves the use of a sociocultural method.

The sociocultural method, which is based on the understanding of the historical and cultural era as a holistic system, allows carrying out research of the educational process and taking into account the peculiarities of 
the fourth industrial revolution.

\section{DISCUSSION}

Problems of higher education which are investigated from the point of view of philosophy of education have received some coverage in literature. The research that characterizes the conditions and factors, contradictions and trends of development of higher vocational education in the modern world [2;3], as well as the work summarizing the experience of functioning and improvement of national educational systems are of interest for consideration of our topic. $[1 ; 4 ; 19$. ]

Of particular interest is the research of scientists who analyze the essence and problems of digitalization of the educational process. In particular, the conditions for the formation of an educational environment on the basis of ICT are presented in a number of works by I. G Zararova, V. A. Dmitriev D.A. Kastornova, I. V. Robert, Yu. A. Prozorov, etc.) [7;13.]. Avtors show that experience in the educational environment enables different options for the formation of an educational environment based on information and communication technologies (ICT) in professional educational organizations depending on the level of readiness of the pedagogical team, interaction of all participants of the educational process, equipping the university with ICT facilities. Mavlyutova G. A, Loginov N., Ustyuzhanina S. G. Evsyukov, Strekalova N.B. explores contradictions and risks in digital education of students and also tries to determine the most optimal methods of education from the point of view of students. [10;17;18;].

\section{RESULTS}

At the beginning of the study, we need to understand what "digitalization" involves in higher education and whether this process entails a change in the educational paradigm and a transformation of the relationship between the components of education. The analysis of scientific publications on this subject has shown that the digitalization of higher education involves the wide and active use of information and communication technologies (ICT). At the same time, it is considered that "the introduction of information and communication technologies through digital repositories, cloud services and social networks will allow teachers of educational organizations to introduce active forms of student education in a mixed environment based on the theory of social constructivism and project training and situational training" [5, p.7]. According to experts of the Higher School of Economics of Russia, the essence of digital transformation is to effectively and flexibly apply the latest technologies to transition to a personalized and result-oriented educational process. [11.]The introduction of digital technologies will require a review of the content of professional training of modern specialists, including scientific and pedagogical workers. Readiness of educational institutions for professional training of specialists of digital society will require not only further technical and technological modernization of the sphere of education, but also training (retraining) of faculty: development of digital literacy; Building the ability to digitize educational and methodological material and use it in pedagogical practice; The ability to develop electronic textbooks with elements of interactive technologies and programmable learning and to create mass open education courses and conduct the learning process online and/or in a mixed manner that include skills of effective communication [6]. Digitalization in higher education also implies the creation of a fundamentally new information structure for the conduct of the educational process. This structure will provide unlimited access to educational resources for anyone with Internet access. One of the tools of digitalization is the development and introduction of an electronic information and educational environment (EIOS) into the educational process of the university. EIOS should use modern technology platforms to implement the knowledge flow, allowing all participants to interact effectively in the educational process through synchronous and asynchronous communication. The introduction to EIOS allows you to study independently of the teacher 's and student 's location. EIOS helps to effectively monitor the learning work of each student. Its range of possible actions is increasing and its responsibility for the impact of training is increasing at the same time [7]. Wide use of multimedia educational materials, which are developed taking into account the requirements of pedagogical design and to a large extent removes the responsibility of teachers for "delivery of educational content" and allow to concentrate on pedagogical support of students and organizational, pedagogical and educational work. With EIOS operating, students and teachers gain unprecedented control over their information space and its sharing. Their capabilities for self-control and mutual control and to generate interest in learning for meaningful learning have expanded. Digital technologies, which are highly likely to become widespread in the university environment, also include drones (unmanned aerial vehicles).

As noted earlier, the Internet creates unlimited access to information resources. However, unrestricted access to information resources does not automatically improve the quality of the educational process. Information alone does not mean education. Research literature on digital education strategy, in addition to 
the dignity of this type of learning - unlimited access to educational resources, has also revealed the problem of digital competence of students. Modern students, those born in the 21 century, according to the concept of DigitalNatives M. Prenski, have innate knowledge about digital technologies and perceive the digital world as everyday and feel in the flow of multitasking and are used to the interactivity of gadgets and to their own activity in social networks to speed in the world of video games [13]. On the basis of this concept, many researchers have stated that modern students have different abilities and capabilities, so the educational process must be organized differently. Undoubtedly, most students before entering higher education have extensive experience in the application of digital technologies, after compulsory (secondary) education. But, basically, these technologies are related to the skills of finding the necessary information in Internet resources and creating electronic presentations. Having experience with digital technology, there is a high probability that the student has an excessive self-esteem about the level of ownership of digital technology, which can negatively affect their activities during the training process. Undoubtedly, the search for information through the Internet resources significantly reduces time, but leads to the fact that students, using other people 's ready-made texts, lose the ability to think critically, develop "fragmented thinking." Any training is carried out with the help of a "mediator," and this mediator is a textbook. In electronic training "intermediary" is not a paper medium - a textbook, which presents educational information in a certain field of knowledge, i.e. not all "holistic picture" of educational information is visible, but only part of it, "fragment of the picture." At the same time, information is perceived as absolutely true and correct without reflection and reflection. However, empirical research shows that familiarity with the technology does not mean a student 's understanding of patterns of its use. With wide access to gadgets, students experience difficulties using digital technologies in the educational context [5, p. 86]. Constant immersion in the redundant information environment leads the student to apply individual information avoidance tactics (the phenomenon of information output) and the essence of which is that the person ignores the relevant useful information because it is too much to understand it and accept it [16]. According to B. Schwartz, there is a paradox of choice that manifests itself in the fact that "there is a refusal to understand information and fix on a quick solution" [20, p. 28.].

This means that the student has difficulty with the amount of educational information and the tasks assigned to him and therefore chooses the lightest or first solution. There is a paradox that despite information literacy and the student cannot select the necessary and sufficient sources of information. The choice results in a random and not always correct source of educational information. In such conditions of one of the main tasks of the teacher is to teach students to study: how to take necessary and to cut unnecessary (excessive) information, where to take it. Experts also note the inevitable rise of risks of digitalization of the educational process. The famous expert in the field of IT security N.I. Caspian in her speech at the Parliamentary Hearings in the State Duma (March 2018) outlined the main risks of wide introduction in all spheres of life of such technologies as uberization and "big data" and blockchain and virtual reality. [8] Risks include the possibility of losing basic cognitive competences (writing, calculation, reading, logic), which should lead to a decrease in the quality of education; leak of personal data; Loss of privacy; "public" model of the teacher/teacher which produces high requirements to his psychological qualities; growth of the conflicts; Leakage of personal data abroad; "Leaking" talented youth and teachers abroad; Changing the skill requirements of specialists, which is reflected in reducing the need for an "intelligent" specialist and "gravity" to his technological image; Automation and robotics of activities; The increase in productivity and efficiency of production and, as a result, the loss of jobs and unemployment and the social tension of the tuneyadets layer.

\section{CONCLUSION}

The social transformations that society periodically experiences call for its modernization. The modernization of society is carried out by various means, among which education plays a major role. In turn, it is necessary to modernize the educational process to meet the demands of the new time. The tools for modernizing social relations tend to derive from the nature of society 's transformation. The Fourth Industrial Revolution (Industry 4. 0.) and the essential content of which is the formation of a digital society. The digital society in which the digital economy plays a significant role and sets fundamentally different trends and is oriented to the training of specialists at a qualitatively different level. And the fact here is not even that a number of specialties from the former economy will not only lose their demand or disappear from the labor market at all. A lot of things will depend on that how concrete knowledge and skills and umeniya received in the course of training will be coordinated with a format of digital economy which will undergo continuous and rather rapid changes. In this regard, the scientific and educational community came to believe that in the era Industry 4.0. The instrument of modernization of the educational process in a modern university should be its digitalization. We set ourselves the task on the basis of theoretical analysis to identify the essence and main 
directions and contradictions and risks of digitalization of the educational process in the university. During the theoretical process, the essence of the term "digitalization" was revealed and a list of digital technologies significant for the development of society (cloud, cognitive, big data technologies and the Internet of Things) was established and a list of key digital competences of a modern specialist was defined and systematized. Along with the positive aspects of digitalization of education, the authors note possible negative changes in this sphere:Loss of basic cognitive competences and reduction of the general level of training and reduction of the need for an "intellectual" specialist and avoidance of fundamentality and high requirements to psychological qualities of the teacher and reduction of personal contacts and "leakage" of talented youth and teachers abroad and reduction of the number of students.

In our view, in order to overcome contradictions and risks of digitalization of the educational process in the university, it is necessary to solve the following tasks at a time and in a coordinated manner: to develop the physical infrastructure. This includes the construction of data centres and the introduction of new communication channels and devices for the use of digital training and methodological materials; Implement digital programs that involve the creation and testing and use of teaching and methodological materials using machine learning and artificial intelligence technologies; Phase out paper media and switch to online training; Establish a universal student identification system; Develop new learning management systems that is programs for administration and control of training courses. Such applications provide students with equal and free access to knowledge as well as learning flexibility.

\section{REFERENCE LIST}

Choshanov M. A. (1989) They learn from mistakes. Soviet pedagogy. №. 9. Pp. 40-44. (in Russ).

Ershov B.A. (2010) The Russian Orthodox Church and secular power in the Voronezh province in the XIX early XX centuries. GOU VPO "Voronezh State Technical University". Voronezh. 167 p. (in Russ).

Ershov B.A. (2010) The system of spiritual education in Voronezh province in the 19th century. Education and Society. №. 5 (64). Pp. 105-108. (in Russ).

Ershov B.A., Fursov V.N. (2018) The Russian Church in the State Mechanism of Russia. Bulletin SocialEconomic and Humanitarian Research. № 1. Pp. 32-37.(in Engl).

Ershov B.A., Perevozchikova L.S., Romanova E.V. (2019) Globalization and Intensification of Spiritual Values in Russia in the Philosophical Aspect. 6th International Conference on Education and Social Sciences Abstracts \& Proceedings. Pp. 208-212. (in Engl).

Ershov B.A., Perevozchikova L.S., Romanova E.V., Ashmarov I.A. (2019) The Concept of Spirituality in Social Philosophy. Smart Innovation, Systems and Technologies. T. 139. Pp. 688-694. (in Engl).

Kholodnaya M. A. (2000) Formation of personal cognitive style of a student as one of the directions of individualization of training. The school of technology. №. 4. Pp. 12-17. (in Russ).

Perevozchikova L.S., Ershov B.A., Ashmarov I.A., Volkova E.A. (2017) Role of Russian Orthodox Church in life of peasants in Russia in XIX - the beginning of the XX-th centuries Bylye Gody. Russian historical journal. №. 43 (1). Pp. 121-128. (in Engl).

Pimenova J1. M. (1959) On the formation of high school students ' independence and activity as personality traits. Soviet pedagogy. №. 5. Pp. 55-59. (in Russ).

Polovnikova N. A. (1969) On the theoretical foundations of educating students cognitive independence in teaching. Kazan. P. 204. (in Russ).

Pozdnyakov S. N. (2000) Productive training and information technologies. The school of technology. №. 4. Pp. 119-127. (in Russ).

Romanova E.V., Perevozchikova L.S., Ershov B.A. (2017) The Lifestyle of the Human Being in the Information Society. 3rd International Conference on Advances in Education and Social Sciences Proceedings of ADVED Pp. 950-954. (in Engl).

Saidashev A. Z. (1985) Activation of cognitive activity of students in problem learning by means of cinema and demonstration experiment: disser. Candidate of pedagogical Sciences, KSPI. 197 p. (in Russ). 
Proceedings of SOCIOINT 2020- 7th International Conference on Education and Education of Social Sciences, 15-17 June 2020

Skotnikova I. (2000) Our friend the computer. Teacher. № 2. P. 59. (in Russ).

Talyzina N. F. (1985) Psychological and pedagogical bases of educational process automation. Psychological-pedagogical and psychophysiological problems of computer training. M. 135 p. (in Russ). 